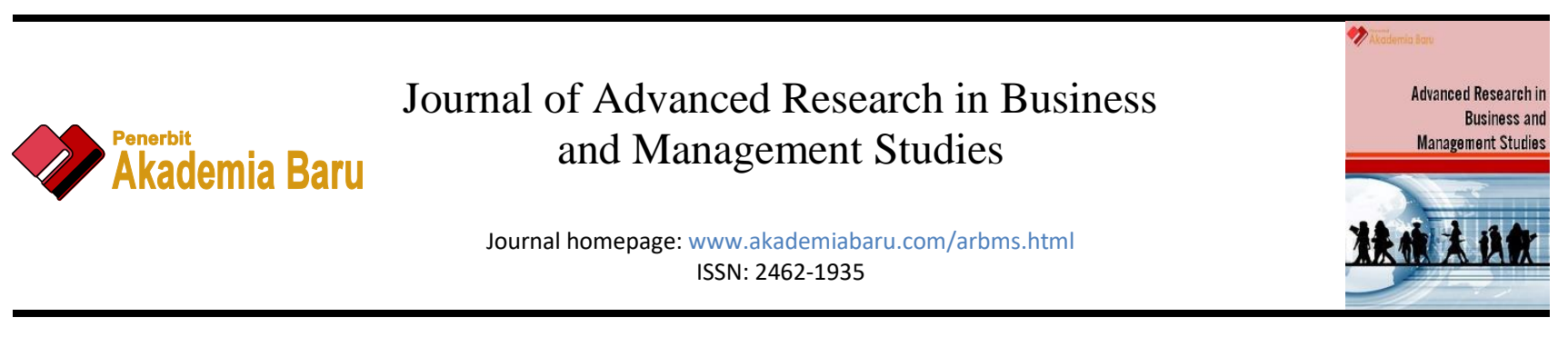

\title{
Issues with New Service Development Process in a Telecommunication Service Provider
}

\author{
Hafizah Zainol Abidin ${ }^{1,}{ }^{*}$, Rudzidatul Akmam Dziyauddin ${ }^{1}$, Kamilah Radin Salim $^{1}$ \\ 1 Razak Faculty of Technology and Informatics, Universiti Teknologi Malaysia, 54100 Kuala Lumpur, Malaysia
}

\begin{abstract}
The research addresses the issues of an existing New Service Development (NSD) process, which is based on the waterfall method at an Internet Service Provider (ISP) in Malaysia. In this particular ISP, account managers and pre-sales personnel respond to the corporate customers' requirements as and when needed. Not all requirements can be met with existing services. Some requires customization and new service development may reach up to a year which is way beyond the customers' deadline. Therefore, this research aims at gauging the issues with the existing NSD process flow by investigating the relevance of the existing method to cater the current market demand including the evolution of technology. The research was conducted using qualitative method. Account managers and pre-sales personnel were interviewed to understand the issues they face with the existing NSD process flow. The semi-structured interview responses were analysed according to themes deduced from the interview transcripts. The main issues highlighted by the interviewees were high dependencies on technology and delivery partners resulting in high out-payment as well as low profit margin and long process for service readiness. All the interviewees agreed that the existing NSD process flow needs to be improvised to cater for the ever-changing market trends. In this research, the interviewees provided suggestions on improvements to the NSD process. In conclusion, the improved NSD process could essentially lead to an efficient service development process and hence facilitating the ISP's competitiveness in the industry world.
\end{abstract}

Keywords:

Product development, service

development, customer,

telecommunication, presales

Copyright @ 2020 PENERBIT AKADEMIA BARU - All rights reserved

\section{Introduction}

Globalisation and market expansion brings competition to another level. It results in stiff competition faced by organisation. Prior to globalisation, organisations face competition from the local industry players. However, as the market expands and trading globally has become wider, competition from global players arise and keep on increasing [1]. Organisations in all industries face stiff competition from both local and global industry players. Firms are exposed to competition from new and existing firms in the market. In order to stay afloat in the industry, it is imperative for an organisation to keep on adding value to its business. In this dynamic economic landscape, organisations struggle to improve performance and stay ahead of their competitors [2-5]. One way of maintaining its position is by investing and initiating a new product [3, 4]. A recent publication

\footnotetext{
* Corresponding author.

E-mail address: hafizah.za@gmail.com

https://doi.org/10.37934/arbms.19.1.2941
} 
conceptualized the notion that service development helps an organization's management to improve performance, achieve differentiation and secure competitive advantage $[3,4,6,7]$. A new product can either be new-to-the-market, innovation of existing products or an extension to existing product $[8,9]$. New product development can also be regarded as the development of new products, improvements and modifications to existing products or new brands via the research and development outcome of the firm $[9,10]$. Organisations adopt New Product Development process in developing the new product. A new product can either be tangible or intangible, depending on the industry the organisation is in. In the case of telecommunication industry, new product is often referred to intangible products, whereby these organisations will develop new services to serve the market's demand and needs.

With the advancement of technology, products are innovated and invented on a relatively fast pace. This is particularly true in a high technology traditional industry such as telecommunication where the technology changes faster than the product development in the service provider environment. Globally, the telecommunication industry expands rapidly [11]. Telecommunication industry is approaching saturation point in some countries [4]. As technology evolves rapidly, obsolesce is inevitable [9]. Therefore, a shorter product life cycle can be seen on the existing product offering [3]. This fast-changing pace requires organisations to be on par with the technology development and customers' demands $[3,9]$. Companies that have faster time-to-market gains first mover advantage $[3,4,9]$. As a result, firms are looking at ways and methods to reduce the time-tomarket in order to gain the competitive advantage [11, 12].

Organisations in the telecommunication industry may adopt the same method in developing or improving its existing services offering. New service development may involve developing a totally new-to-the-market service or innovating existing service packaging and offerings. Innovation has also been of great interest to organisations leaders all over the world [13] . Other researches highlighted that innovation helps organisations to achieve or improve their performance $[4,12,14]$. This is agreed by another author whom also added that service innovations are adopted by leaders to enable an organisation to upkeep with the ever-changing market dynamics [15]. Achieving innovations in service by integrating external stakeholders such as customers, suppliers or distributors will enable service-oriented firms to achieve its business performance goals and maps its business direction [3, 14, 16]. Telecommunication service provider aiming to improve its business performance have to take strategic moves and coordination as well as focus on integration tasks in order to reap the full benefits of service innovation [3, 13].

In the context of Malaysian telecommunication industry, the industry players include the Internet Service Providers (ISP). The ISP can either offer fixed or mobile telecommunication services. This paper focuses on a particular ISP offering both fixed and mobile services to the mass market consumers and corporate customers. Corporate customers are enterprise customers from the public and private sectors. As they fall under the business-to-business segment, they are assigned dedicated pre-sales teams comprising of account managers and technical solution consultants. The corporate customers' accounts team faced daily issues of existing services not complying to the corporate customers' requirements. This is mainly due to long process taken to productise a particular service, be it new or innovating an existing service offering. As such, the study is aimed at revealing the issues pertaining to the existing service development process and offer improvement and enhancement suggestions to the existing process. The study focused on the views of the "frontliners" whom are the main person in charge when dealing with the customers' requirements. It has been proven by a study that front-line employees bring valuable inputs to the table in developing or innovating a new service $[16,17]$. The front-line employees understand the customers' intended value propositions 
hence they can help to integrate these values with service knowledge and the ISP's capability into the service development process $[16,17]$.

The remainder of this paper is structured as follows: Section 1.1 provides a literature review. Section 2 presents the research methodology and Section 3 highlights the outcome of the study. In Section 4, some practical implications in the telecommunication industry are proposed and concludes the paper.

\subsection{Literature Review}

New product development (NPD) becomes the lifeline of organisations to regain competitive advantage and fuels the best hope for future positive growth [3]. A structured method is one of the key determinant in successful NPD $[2,12]$. Utilising the right technique and method can ensure the successful product development project undertaken by firms and assist firms in achieving greater performance [12]. Most literatures highlight the waterfall or stage-gate method in developing a new product. With stage-gate process, each gate will have its own evaluation process. The proposed product or service can move forward to the next stage after it passes the individual gate barrier evaluation. A study highlighted that stage-gate evaluation reduces the likelihood of new product failures since each barrier has its own evaluation metrics [8]. There are a few popular product failure cases due to bad planning and failure to evaluate the new product before launching it into the market [8].

Another literature, proposed a five-stage process gate in a new product development process. This is an improvement of the six-stage gate he highlighted earlier [8]. The author suggested that firms should not remain in the same industry boundary in order to stay competitive. Based on this, an improved model was proposed. The improvement was made based on her investigation of previous new product failure cases. The six-stage process includes idea discovery, scoping, building business case, development, testing and validation, and finally launch. His single modification on the new product development process is as shown in Figure 1:

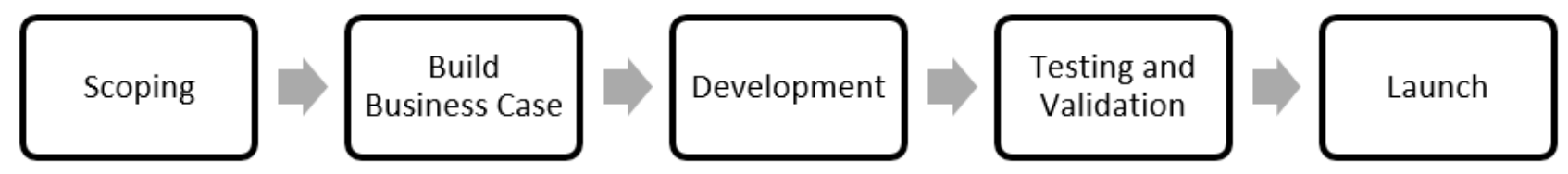

Fig. 1. Proposed modification on New Product Development Process [8]

He suggested that the idea generation to be incorporated within scoping using a proposed matrix whereby organisations should look into expanding their industry boundary and investing in a blue ocean. However, his modification is solely based on his investigation of tangible products failure in the manufacturing industry. It is worth noting that he did not study the stage-gate process for intangible products in the services industry. The proposed model was not tested against a service development in the service industry, which limits the work.

Another research on the other hand, classified new product development process as a thirteengate process [18]. The stages are ideas brainstorming, idea screening, preliminary market assessment, preliminary technology assessment, preliminary production assessment, preliminary financial assessment, market study, product development, internal product assessment, customer focus group test, market assessment, financial evaluation prior to launching, and finally market launching. Brainstorming and idea screening can be obtained via market study or by incorporating customers' needs $[17,19]$. Incorporating customers' needs can be done by taking into consideration 
input from front-line employees. These employees deal with the customers on daily basis. Thus they may have first-hand information on customers' needs [17]. The "frontliners" can incorporate and align both customers' and organisation's objectives, hence co-creating good value propositions [17]. These thirteen stages however, could have been combined into just five or six phases as per the recommendations in most literature $[6,8,13]$. Although another paper emphasised that omitting a single stage could result in a significant impact to the product development process [18]. This is because some of the stages are mere repetitions of the work been done in the previous stage. With lesser gates, the product or service development could have been expedited and eventually fasten the product launch in the market $[3,18]$.

Recent publication highlighted that the most important phases from the thirteen-gate process and reduced it to just seven phases [18]. The simplification was achieved by studying failure cases of product development in a medium-sized radio frequency business firms. It is however worth noting that this is a product development process instead of service development. The new product development failure was due to skipping some stages, lack of market study and some tasks went beyond the capacity of some employees as they are more labour intensive than the other. As the firm only used partial developed process without profitability and market study, internal problems arose. Also, due to high number of gates involved, the development of many products simultaneously proved to be a challenging feat for the firm. As such, the simplification and emphasis on certain gates was introduced, as depicted in the Figure 2.

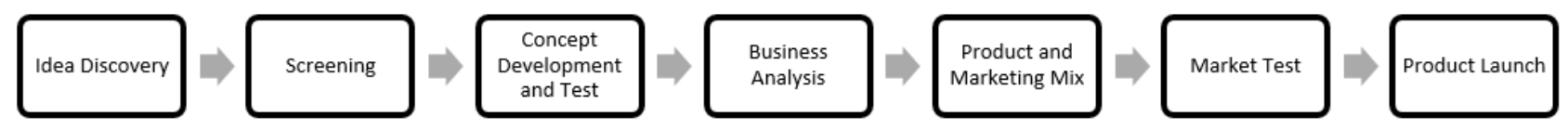

Fig. 2. Simplification of Product Development Gates[18]

The bottleneck of this model is that no real test was conducted on any service development case. Although it can be replicated, it is worth noting that the phase arrangement and evaluation might differ in a service development environment.

Most of the literatures $[2,7,8,13,18]$ emphasised on the importance of evaluation after each phase. As such, a gated process eventually facilitates successful product or service launching. Among the criteria that can be included in the evaluation are consumer satisfaction and financial indicators[7]. As suggested by another study, customer satisfaction can be regarded as one of the critical success factor in an organisation [20]. A proposed new product should not proceed to the next stage if it doesn't pass the evaluation in the earlier stage. Firms could introduce a certain matrix when evaluating at the end of each phase. This was however not discussed in details in any of the literature.

Another research on new product development in manufacturing industry in Jordan, highlighted that organisational capabilities contribute directly to the successful undertake on an NPD activity [21]. Organizational capabilities include technological capabilities, marketing mix capabilities and customer relational capabilities. From the research, customer capabilities do not contribute directly to the success on NPD undertaken by a particular organisation. This contradicts a research carried out by another study that highlighted customer's role as value co-producer $[3,16,17,19]$. New product or services should be driven by market demands, customers' needs and aimed at satisfying customers' requirements $[3,16,17]$. However, it is worth noting that a good new product quality contributes to customer loyalty which in turn translates into bigger market share [3, 21]. Technological capabilities on the other hand do not contribute directly to speed to market and product quality. However, it is worth noting that these dimensions may impact indirectly during the 
development phases. In fact, this research focused on manufacturing firms in Jordan and could not be generalised further in the service industry such as the telecommunication industry. We can conclude that having a gated process together with technological and customer capabilities are crucial in ensuring the successful NPD initiative. This was further discussed and agreed upon by another study done by an industry player [3].

Multiple dynamics contribute to the success of an NPD undertaken by an organisation. Various literatures highlight the importance of integrating these factors into the NPD. They include internal resources, customers, suppliers and technology partners. These factors can contribute directly and indirectly to the success of each NPD activity $[3,7,11,16,17,19]$. This is extremely true in a multidisciplinary product development where customisation in terms of customers' needs are taken into consideration $[3,17,19]$. The lack of literature focusing on telecommunication service development process warranted the needs of this study.

\section{Methodology}

The research was carried out at an Internet Service Provider (ISP) in Malaysia. The research began by evaluating the existing New Product Development (NPD) process in the ISP. Evaluating the existing NPD process will help to uncover the loopholes and issues with existing process and the areas that can be further improved on. Personnel from Pre-Sales and Account Management divisions were interviewed to further understand the problems faced by them when dealing with corporate customers' requirements. They are selected based on their roles as front-line employees with continuous contact with the corporate customers. The purpose of the interview session is to assess and gauge the issues with the current NPD process as well as suggest improvements to it. The semistructured interview questions were aligned to the framework and research objective. The interview questions were drafted to allow flexibility based on the interviewees' roles and feedback during the interview sessions. All the interviewees were asked the same questions and were probed further based on their answers to elicit more elaborate responses.

Ten personnel from this ISP agreed to be interviewed during the study. They were selected based on their involvements in dealing with non-productised requirements when responding to corporate customers' requirements. Face-to-face interviews were carried out with the interviewees who could make the time to meet and consented for the recording. However, five out of the ten interviewees opted for communication via e-mails due to time constraint and job natures that requires them to be on the move most of the time. The same set of questions was sent via e-mails to personnel who agreed to participate in the study. Explanations on the expectations of the study and interview was done both via e-mail and telephone call. They were also probed further via e-mail after getting the first response.

\section{Results}

\subsection{Document Analysis}

Based on document reviews, it is found that the ISP has existing New Product Development process flow, consisting of ten gates, including product exit. However, for each product to be launched in the market, the total number of gates is seven. Each gate is governed by a committee that endorses a set of pre-defined documents before the product development team can progress to the next gate's approval. 


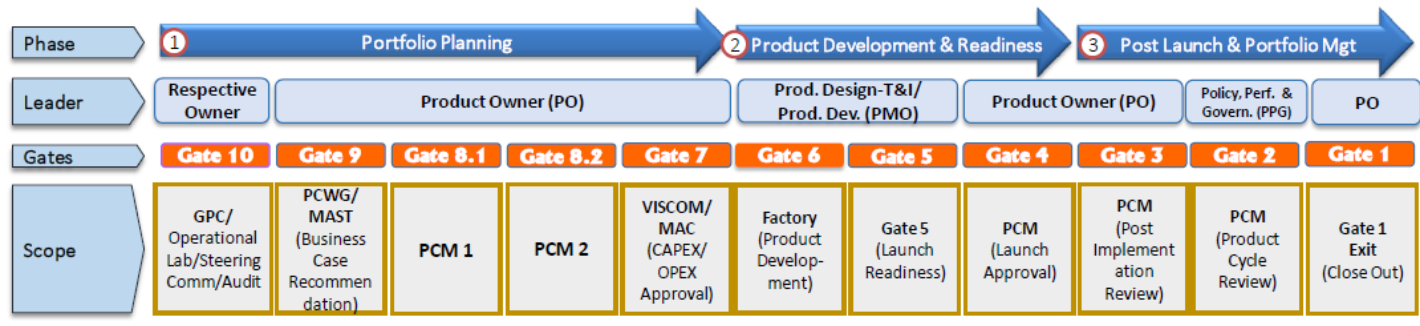

Fig. 3. The Existing New Product Development Process in the ISP

The process to productise begins at Gate 10. This is where ideas and market trends are studied, evaluated and presented to the committee. Respective product owners are also required to present on the proposed solutions to be productised together with the works and plans for the productisation to begin. Apart from that, the product owners are expected to present in-depth justifications on why the product needs to be ready and introduced to the market.

At Gate 9, idea brainstorming and focus groups are expected to be done. Product owner is also expected to conduct an in-depth market and financial analysis for their ideas. However, in the existing practise, there is a lack market forecast and intelligent. Therefore, idea generation is mostly dependent on partners and published market trends. It is also apparent that the productisation process lack input from customer focus group. Some product owners rely solely on the sales' team to get market insights and forecast. However, there are product owners who are oblivious to the market trends and did not do proper market study prior to presenting to the committee in Gate 9.

As can be seen in Figure 3, Gate 8 is divided into two stages although both stages eventually carry the same functions and similar outcomes. At Product Committee Management (PCM), product owners will table out their budget requirements and the committee then decides if the product idea can proceed for budget approvals which is done at Gate 7. At Gate 7, both Capital Expenditure (CAPEX) and Operational Expenditure (OPEX) budget requests are done. Productisation process consumes both CAPEX and OPEX throughout the entire process as it involves a lot of activities and consumes a lot of resources across many divisions.

Prior to Launch in Gate 5, the idea or product concept will be configured and tested in a lab environment. The technology options are then evaluated before finalising the product to be offered to the market. Upon which, the product is finally launched at Gate 4.

From the gated process, it is clear that there is no direct customer involvement in the product development as well as market testing prior to actual market launch. Soft launch was not included in the process. Soft launch, which can act as a source of input in gauging the market acceptance of the product, is crucial in determining the success of the particular product or service.

At a glance, the existing process flow is also longer than the industry standard as discussed in previous section. Based on initial findings, the whole process to productise a product or service is close to two years due to the high number of "Gates" that a product needs to go through. Some of the Gates are redundant as the secretariats consist of almost the same members. At times, there will be incomplete quorum in a particular committee seating hence resulting in the need of a second seating which further delays the product launch. This in turn further lengthen the particular service productisation period. Seating of the previous committee also has to be repeated should there is a query in the subsequent gate. For example, if the committee in Gate 7 queries the decision made in Gate 8, the product owner then has to revisit Gate 8 and present to Gate 8's committee members for re-approval.

Apart from that, the process is not extensive as it does include all the divisions that deal directly with the corporate customers. The product owners have full responsibility of all the stages and have the options to include or not include the other divisions and personnel. For example, there is no 
requirement for the product owners to gather information on market requirements from the Account Managers or Pre-Sales personnel. Therefore, there is no closed-loop of the process.

\subsection{Interview Analysis}

\subsubsection{Issues with existing NPD}

The first section of the interview session is to collect input on the issues with regards to the existing NPD process. From the face-to-face interview sessions, all ten interviewees raised and highlighted the main issues with the existing NPD process. The long-gated process consumes a lot of time for a solution to be productised despite getting a lot of requests and already being offered in the market by other industry players. All of them highlighted the high dependencies on partners' involvement in crafting and delivering proposals based on corporate customers' requirements due to the inefficiency in the existing process. The next subsection lists down the issues raised by the interviewees during the interview sessions.

One respondent commented the following:

"For non-productised solution to be productised, they take a long time. We need to prepare and present to a few councils, have some forecast and assessment on the proposed product, which device and equipment to use and the assurance. From my experience, it took more than a whole year for them to productise (the managed internet service)."

With the long process and the required information to be gathered before a product or service can be productised, most requirements are dealt with by engaging partners which caused further issues. All interviewees highlighted the same issue. The framework matrix on these issues based on interviews is generated using NVIVO, as depicted in Table 1.

Two interviewees commented that they are unaware of the new product development process existence in the ISP. This clearly signifies the main issue in the new product development process since pre-sales personnel are unaware and not involved in the productisation process. One interviewee stated the following,

"I don't know the process to productise but a customised solution can be productised once it reaches a certain amount of successful implementation."

This interviewee assumed that the solution can be productised should it meet a certain number of successful implementation but she is not confirmed on the whole process and the method to get the solution productised.

Another interviewee, on the other hand, concurred on the non-existence of the process. He commented the following,

"There is no process on new product development. We have to rely on partners and some partners don't give feedback but some give proposals."

He further clarified that due to no process on new product development, he had to heavily rely on partners in completing the solution proposals although not all partners will feedback on time. 


\section{Table 1}

Issues with existing product development process as highlighted by interviewees

\begin{tabular}{|c|c|}
\hline Interviewee & Issues \\
\hline $\begin{array}{l}\text { Solution Consultant } \\
\text { (SC) }\end{array}$ & $\begin{array}{l}\text { SC has to provide the forecast for each requirement that needs to be } \\
\text { productised by SC don't normally have this information. It could take more } \\
\text { than a year to productise a solution. } \\
\text { Most of the time, we relied on technology partners and solution integrators. }\end{array}$ \\
\hline $\begin{array}{l}\text { Solution Consultant } \\
\text { (SC) }\end{array}$ & $\begin{array}{l}\text { There is no firm process (to productise) in black and white. } \\
\text { We have (sent out) too many proposals which we are not receiving Purchase } \\
\text { Order (PO) and partners tend to lose confidence (with the particular ISP). } \\
\text { The (technical) competency will be relied on partner. Hence, if there is no } \\
\text { proper agreement or project management, we might face hiccups during } \\
\text { (project) delivery. }\end{array}$ \\
\hline $\begin{array}{l}\text { Solution Consultant } \\
\text { (SC) }\end{array}$ & $\begin{array}{l}\text { A lot of unproductised requirement is dealt by engaging partner during the } \\
\text { design and delivery stage due to expertise limitation internally at the moment. }\end{array}$ \\
\hline $\begin{array}{l}\text { Solution Consultant } \\
\text { (SC) }\end{array}$ & $\begin{array}{l}\text { There is no process on new product development. We have to rely on partners } \\
\text { and some partners don't give feedback but some give proposals. Sometimes, } \\
\text { we face delay during (project) implementation if we rely on partners. }\end{array}$ \\
\hline $\begin{array}{l}\text { Solution Consultant } \\
\text { (SC) }\end{array}$ & $\begin{array}{l}\text { Partner will provide the proposal of proposed solution for their portion only, } \\
\text { which is mostly from their standard template and datasheet while The ISP has } \\
\text { to the overall consolidation. } \\
\text { Some partners are involved on providing end-to-end/overall proposals. At } \\
\text { times, we do get comprehensive proposals from partners. }\end{array}$ \\
\hline $\begin{array}{l}\text { Solution Consultant } \\
\text { (SC) }\end{array}$ & $\begin{array}{l}\text { If the business case is deemed not relevant such as low demand in forecast, } \\
\text { therefore the plan to productise will not be approved by the management. } \\
\text { When we rely on partner, there's a high risk that partner may backout and the } \\
\text { ISP has to bear this risk. There will issues on operations (post-sales) too when } \\
\text { we rely on partners. }\end{array}$ \\
\hline Account Manager (AM) & $\begin{array}{l}\text { For complex solution, we usually need to do Proof Of Concept (POC) together } \\
\text { with partner in order to measure the ability and effectiveness of the proposed } \\
\text { non-productised solution. }\end{array}$ \\
\hline Account Manager (AM) & $\begin{array}{l}\text { I don't know the process to productise but a customised solution can be } \\
\text { productised once it reaches a certain amount of successful implementation. } \\
\text { Most times, we relied on partners. } \\
\text { Some partners can support } 24 \times 7 \times 4 \text { hours Mean Time to Respond Resolve. } \\
\text { Some partners on the other hand have limitations due to limited number of } \\
\text { resources. }\end{array}$ \\
\hline Account Manager (AM) & $\begin{array}{l}\text { Partner has no belonging or ownership of the account. Therefore, the ISP } \\
\text { needs to interfere in coming out with the proposal. Partner can't provide } \\
100 \% \text { post-sales support too. } \\
\text { At this point, there is no process that involves sales in productising the } \\
\text { product. }\end{array}$ \\
\hline
\end{tabular}

An Account Manager commented that the Product Owners have not sent out survey questionnaires on market trends to them. The Account Managers manage the corporate customers on daily basis and would have valuable market insights. The lack on input from them lead to uncompetitive product offering as well as product that do not meet the market needs. Telecommunication industry evolve on a very fast pace. As such, it is important to always engage the Account Managers and get their feedback on the popular requests currently trending in the market as they are the "front-liners". This survey should be done at least once a year to ensure the ISP's continuous relevance in the market. They represent the voice of the business and are the first to interact with customers. In other words they are organisation's ambassadors. 
Apart from that, all interviewees highlighted the high dependency on partners' involvement in coming out with the technical proposals to be submitted to the corporate customers. This clearly shows the inefficiency and issues with the existing NPD. Most of the requirements received by the Solution Consultants and Account Managers are non-productised, hence there is a need to work with the partners.

\subsubsection{Timeline}

When dealing with non-productised requirements which involved partners, there will be issues with timeline too. The interviewees also highlighted on proposal submission timeline when depending on partners as well as timeline with the existing NPD process. The statements regarding timeline are tabled out below, using NVIVO software. High reliance on partners when delivering the proposed solutions could result in interruptions and delays during project implementation thus delaying the certificate of acceptance sign-off. This in turn results in delayed revenue collection from the customers. Delayed revenue realization will in turn affect the "bottom-line" of the ISP. Table 2 summarises all timeline related statements mentioned by the interviewees.

\section{Table 2}

Issues with existing new product development process resulting in stretched timeline

\begin{tabular}{|l|l|}
\hline \multicolumn{1}{|c|}{ Interviewee } & \multicolumn{1}{c|}{ Response } \\
\hline Solution Consultant (SC) & $\begin{array}{l}\text { For un-productised to productised, they take a long time. Among the information } \\
\text { required are forecast and assessment of the product, which device to use and the } \\
\text { assurance process. All these information must be presented to the councils. From my } \\
\text { experience, it took a whole year for them to productise. }\end{array}$ \\
\hline Solution Consultant (SC) & If there is disturbance (in partner's involvement), there will be project delays. \\
\hline Solution Consultant (SC) & $\begin{array}{l}\text { Some partners that feedback on the requested proposals, they normally give } \\
\text { proposals within 7 to 14 days. } \\
\text { At times, we do face delay on implementation. }\end{array}$ \\
\hline Solution Consultant (SC) & $\begin{array}{l}\text { Some partners provide proposals at the very last minute, where some time up to } 2 \text { or } \\
\text { 3 days after the deadline. }\end{array}$ \\
\hline Account Manager (AM) & There will be impact to commercial (pricing) and project delivery timeline. \\
\hline Account Manager (AM) & $\begin{array}{l}\text { Delivery timeline is most of the time affected. Sometimes the ISP commits to three } \\
\text { months of project delivery period, but the partners are short of staff so timeline is } \\
\text { stretched. We don't get this much problem if we rely on our internal resources (staff) } \\
\text { especially when we get good project managers. }\end{array}$ \\
\hline Account Manager (AM) & $\begin{array}{l}\text { It is difficult to get partners to assist us on ad-hoc basis because they are also } \\
\text { supporting other customers or service providers. }\end{array}$ \\
\hline
\end{tabular}

Six interviewees concurred that dependency on partners could be detrimental to the performance of the ISP.

High reliance on partners lead to other problems such as bad quality and incomplete proposals received from the partners. Interviewee number 7 , mentioned the following:

"Partner will provide the proposal of proposed solution for their portion only, which is mostly from their standard template and datasheet while the ISP has to do the overall proposal consolidation."

When the partners submitted the proposals at the very last minute, the pre-sales personnel will have a hard time reviewing, consolidating and finalizing the submissions to the corporate customers.

Meanwhile, interviewee number two, highlighted the following, 
"Some partners revert quite late (very near the tender submission deadline) and the price sometimes are not up to expectations (due to multiple layers involved such as distributor to reseller)."

Corporate customers would have their planned budget for each of their requirements. When there are partners involved in crafting and complementing the solutions proposals, the final price to be summited to the corporate customers could be higher than the budgeted amount thus impacting the competitiveness of the said ISP.

One interviewee revealed the following issue when involving partners in preparing the solutions proposal and delivering the project after being awarded.

"Delivery timeline is most of the time affected. Sometimes the ISP commits to three months of project delivery period, but the partners are short of staff so timeline is stretched. We don't get this much problem if we rely on our internal resources (staff)."

As such, the ISP needs to relook into the NPD process and improve on it to reduce the reliance on partners when submitting solution proposals to their corporate customers and when delivering the project awarded to them.

\subsection{Suggestions}

As highlighted in the previous subsections, some interviewees relied heavily on partners or solution integrators in responding to the corporate customers' requirements. This is due to unproductised requests received from the corporate customers. At the end of the interview sessions, the interviewees gave suggestions on the improvement that can be done by the Product Team in productisation process. The following framework matrix summarises all the suggestions raised by the interviewees.

Two interviewees suggested that Product Owners distribute quarterly Go-To-Market survey to the Account Managers. As they interact with the corporate customers, they can gain valuable inputs and insights on the trending market offering as well as market requirements. Therefore, their input in the idea generation phase is crucial. The account managers can also help product owners to filter the technological partners preferred by the corporate customers. Customers in different sectors have different views and preferences on the technology partners available in the industry. Account managers can also provide input on the constraints faces by the corporate customers caused by external factors such as economy and politic situations. Some corporate customers, have budget constraints, therefore preferring a simpler and less known technology partners and brands. Account managers, too, should have some say on the proposed business models for all the products and services. Some corporate customer prefer a one-time investment whereas some prefer the lease-toown model with staggered payments throughout the contract period.

Another interviewee, on the other hand, suggested that Solution Consultants (SC) to be one of the stakeholders in the productisation process, focusing on the technical aspects of the product features. One SC commented,

"SC can be one of the stakeholders/team members in terms of developing or identifying repetitive vertical solutions. There should be close collaboration between SC and product house as SC faces the market".

SCs are responsible in finalising the technical proposal based on the customers' requirements. Therefore, they are in a much better situation to identify repetitive requirements or identify the most 
requested technology partners in the particular sector they are working on. SCs are also responsible in evaluating all the possible options when preparing the technical proposal. Therefore, the in-depth study and evaluation can be used to further support the productisation justification needed in Gate 10 and 9. SCs would also have the input on "must-have" and "nice-to-have" technical features. This is a valuable input when crafting the service commercial packages and pricing with compulsory and additional specification options.

\section{Table 3}

Improvement suggestions

\begin{tabular}{|c|c|}
\hline & Suggestions \\
\hline $\begin{array}{l}\text { Solution Consultant } \\
\text { (SC) }\end{array}$ & $\begin{array}{l}\text { Productise more services and solutions thus may result in better allocation of } \\
\text { resources for design, deployment, installation and maintenance, better planning of } \\
\text { sparing. } \\
\text { Building internal competency is very important. } \\
\text { reduce the dependency on partners/ vendors in designing and delivery if these } \\
\text { brands are productised. Once that is in place, all the relevant processes for these } \\
\text { repetitive solutions can take place. } \\
\text { SC can be one of the stakeholders/team members in terms of developing or } \\
\text { identifying repetitive vertical solutions. There should be close collaboration between } \\
\text { SC and product house as SC faces the market. }\end{array}$ \\
\hline $\begin{array}{l}\text { Solution Consultant } \\
\text { (SC) }\end{array}$ & $\begin{array}{l}\text { To have more "customer friendly" product offering since our current product offering } \\
\text { is quite rigid. If we really want to venture into new technology offering like SD-WAN, } \\
\text { the product has to be neutral not just specific to only one brand. It seems like now } \\
\text { we're still selling the brand rather than the technology or solution. }\end{array}$ \\
\hline $\begin{array}{l}\text { Solution Consultant } \\
\text { (SC) }\end{array}$ & $\begin{array}{l}\text { Product should have several internal input from field from various customers } \\
\text { segments such as Retail \& Commercial, Services, Key Accounts and Public Sectors. By } \\
\text { that input, they would be able to get the right input \& deriving a good product that } \\
\text { suits respective target market. }\end{array}$ \\
\hline $\begin{array}{l}\text { Solution Consultant } \\
\text { (SC) }\end{array}$ & $\begin{array}{l}\text { Product team should productise different brands (neutral - not pro to only one brand) } \\
\text { under the same product portfolio. } \\
\text { Product need to knows/catch up with the current customers' } \\
\text { need/trends/technologies/environment/requirements - so that they have good } \\
\text { strategy and speed up their go-to-market, and thus make the product marketable to } \\
\text { the industries }\end{array}$ \\
\hline $\begin{array}{l}\text { Solution Consultant } \\
\text { (SC) }\end{array}$ & $\begin{array}{l}\text { Lessen the productising process in order to cater the repetitive requirements from } \\
\text { different customers. Then we could get internet support rather than having partner } \\
\text { and increase the outpayment. } \\
\text { Keep the process less complicated and less approval paper. }\end{array}$ \\
\hline Account Manager (SC) & $\begin{array}{l}\text { Product to be more flexible in terms of the brand they carry; low end to high end } \\
\text { brand. } \\
\text { brand of switches/routers. Wireless solutions - our product is very rigid on the } \\
\text { solution (features/business models) - expensive charges. Our partners can provide } \\
\text { similar service with lower charges. } \\
\text { Quarterly survey to sales people. }\end{array}$ \\
\hline Account Manager (AM) & $\begin{array}{l}\text { Provide Go-To-Market survey to sales people. Product has to be more open and listen } \\
\text { to us that are fronting the customers. }\end{array}$ \\
\hline
\end{tabular}




\section{Conclusion}

Based on the initial analysis of the completed interview session, there seems to be issues with the existing NPD process that resulted in high reliance on partners and solution integrators involvement in responding to corporate customers' requirements. New services can only be "productized" or established after going through all the gated process which could take up more than a year. The study also confirmed that the high dependency on partners in completing the solution proposals resulted in other issues such as stretched timeline in completing both the proposal and the project. This subsequently would impact the profitability and "bottomline" of the ISP.

This study also provides several useful suggestions on how the ISP could improve their current NPD process flow. The findings were presented to the ISP's product team to assist them in their transformation and process improvement. The findings implications of this study is not only beneficial for the ISP but also for other firms in the telecommunication industry. Other firms could take the suggested improvement plans and adopt them in their NPD process. In the future, the study can be replicated in other ISP's environment for further validation and become a part of industry benchmarking practice.

\section{References}

[1] Lagrosen, Stefan. "Customer involvement in new product development." European Journal of Innovation Management (2005). https://doi.org/10.1108/14601060510627803

[2] Graner, Marc, and Magdalena Mißler-Behr. "Key determinants of the successful adoption of new product development methods." European Journal of Innovation Management (2013). https://doi.org/10.1108/EJIM-08-2012-0084

[3] Yan, Jie, Le Wang, and Jie Xiong. "Alcatel-Lucent falls, Huawei ascends: New product development makes the difference." Journal of Business Strategy (2017). https://doi.org/10.1108/JBS-01-2016-0001

[4] Yang, Chang-Gyu, Silvana Trimi, and Sang-Gun Lee. "Effects of telecom service providers' strategic investments on business performance." Industrial Management \& Data Systems (2016). https://doi.org/10.1108/IMDS-08-2015-0350

[5] Bhangu, Parneet Kaur. "Persistence of profitability in top firms: does it vary across sectors?." Competitiveness Review: An International Business Journal (2020). https://doi.org/10.1108/CR-12-2018-0087

[6] Tidd, J., and F. Hull. "Managing service innovation: Variations of best practice. Tidd, J. and Hill, F.(ed.) Service Innovation: Organizational Responses to Technological Opportunities and Market Imperatives." (2003): 1-34. https://doi.org/10.1142/9781848161306 0001

[7] Benassi, João Luís Guilherme, Daniel Capaldo Amaral, and Lucelindo Dias Ferreira. "Towards a conceptual framework for product vision." International Journal of Operations \& Production Management (2016). https://doi.org/10.1108/IJOPM-11-2013-0511

[8] Pitta, Dennis, and Elizabeth Pitta. "Transforming the nature and scope of new product development." Journal of Product \& Brand Management (2012). https://doi.org/10.1108/10610421211203097

[9] Adiele, KENNETH C. "New product development and consumer innovative behavior: an empirical validation study." European journal of business and social sciences 1, no. 6 (2012): 97-109.

[10] Philip, Kotler. Principles of marketing. Pearson higher education, 2017.

[11] Dasanayaka, S. W. S. B., Omar Al Serhan, Mina Glambosky, and Kimberly Gleason. "The business-to-business relationship: examining Sri Lankan telecommunication operators and vendors." Journal of Business \& Industrial Marketing (2020). https://doi.org/10.1108/JBIM-06-2019-0303

[12] Yeh, Tsu-Ming, Fan-Yun Pai, and Ching-Chow Yang. "Performance improvement in new product development with effective tools and techniques adoption for high-tech industries." Quality \& Quantity 44, no. 1 (2010): 131. https://doi.org/10.1007/s11135-008-9186-7 
[13] Taghizadeh, Seyedeh Khadijeh, Krishnaswamy Jayaraman, Ishak Ismail, and Syed Abidur Rahman. "A study of service innovation management in the Malaysian telecommunications industry." Global Business and Organizational Excellence 34, no. 1 (2014): 67-77.

https://doi.org/10.1002/joe.21585

[14] Salunke, Sandeep, Jay Weerawardena, and Janet R. McColl-Kennedy. "Competing through service innovation: The role of bricolage and entrepreneurship in project-oriented firms." Journal of Business Research 66, no. 8 (2013): 1085-1097.

https://doi.org/10.1016/j.jbusres.2012.03.005

[15] Ruivo, Pedro, Tiago Oliveira, and Miguel Neto. "ERP use and value: Portuguese and Spanish SMEs." Industrial Management \& Data Systems (2012). https://doi.org/10.1108/02635571211254998

[16] Busagara, Theresia, Neema Mori, Lena Mossberg, Dev Jani, and Tommy Andersson. "Customer information sharing and new service development: is there a link?." The Bottom Line (2020). https://doi.org/10.1108/BL-09-2019-0112

[17] Karlsson, Jenny, and Per Skålén. "Exploring front-line employee contributions to service innovation." European Journal of Marketing (2015). https://doi.org/10.1108/EJM-10-2012-0568

[18] Kim, Yeon-Hak, Sun-Woong Park, and Yeong-Wha Sawng. "Improving new product development (NPD) process by analyzing failure cases." Asia Pacific Journal of Innovation and Entrepreneurship (2016). https://doi.org/10.1108/APJIE-12-2016-002

[19] Aho, Anne-Maria, and Lorna Uden. "Strategic management for product development." Business Process Management Journal (2013). https://doi.org/10.1108/BPMJ-09-2012-0098

[20] Khan, Nusratullah, Muhammad Usman Akram, Asadullah Shah, and Shoab Ahmad Khan. "Important attributes of customer satisfaction in telecom industry: A survey based study." In 2017 4th IEEE International Conference on Engineering Technologies and Applied Sciences (ICETAS), pp. 1-7. IEEE, 2017. https://doi.org/10.1109/ICETAS.2017.8277858

[21] Akroush, Mamoun N. "Organizational capabilities and new product performance." Competitiveness Review: An International Business Journal (2012). https://doi.org/10.1108/10595421211247178 